\title{
Assessment of Progressive Collapse in Multi-Storey Buildings
}

\author{
B.A. Izzuddin ${ }^{1}$, A.G. Vlassis ${ }^{2}$, A.Y. Elghazouli ${ }^{3}$, D.A. Nethercot ${ }^{4}$
}

\begin{abstract}
A simplified framework is proposed for progressive collapse assessment of multi-storey buildings, considering sudden column loss as a design scenario. This framework can be applied at various levels of structural idealisation, and enables the quantification of structural robustness taking into account the combined influences of redundancy, ductility and energy absorption. Three main stages are involved in the proposed approach: i) determination of the nonlinear static response, ii) dynamic assessment using a novel simplified approach based on energy conservation, and iii) ductility assessment at the maximum dynamic deformed configuration. The application of the proposed method is illustrated on a multi-storey steelframed composite building, where the relative importance of various joint details and levels of axial restraint is highlighted. Importantly, the study underlines the inadequacy of prescriptive tying force requirements that neglect ductility issues, and demonstrates that typical composite buildings must rely on bending or compressive arching rather than tensile catenary action for enhanced structural robustness.
\end{abstract}

Keywords: progressive collapse, robustness, steel-framed composite buildings, designoriented method, extreme events, column failure, key vertical element

\footnotetext{
${ }^{1}$ Professor of Computational Structural Mechanics, Dept. Civil \& Env. Eng'g, Imperial College London, SW7 2AZ, (Corresponding author, b.izzuddin@imperial.ac.uk)

${ }^{2}$ Research student, Dept. Civil \& Env. Eng'g, Imperial College London SW7 2AZ

${ }^{3}$ Reader in Engineering Structures, Dept. Civil \& Env. Eng'g, Imperial College London SW7 2AZ

${ }^{4}$ Professor of Civil Engineering, Dept. Civil \& Env. Eng'g, Imperial College London SW7 2AZ
} 


\section{INTRODUCTION}

The UK Building Regulations ${ }^{1}$ has led with requirements for the avoidance of disproportionate collapse, which were formulated in the aftermath of the 1968 Ronan Point collapse. These requirements include i) prescriptive 'tying force' provisions which are deemed sufficient for the avoidance of disproportionate collapse, ii) 'notional member removal' provisions which need only be considered if the tying force requirements could not be satisfied, and iii) 'key element' provisions applied to members whose notional removal causes damage exceeding prescribed limits. The two main shortcomings of the current requirements ${ }^{1,2}$ are that the tying force provisions are unrelated to real structural performance, and that ductility considerations ${ }^{3}$ are neglected at all levels of the provisions. Indeed, the tying force requirements are intended to provide resistance to gravity loading by means of catenary action upon removal of a vertical member, yet the associated ductility demands for specific structural forms can be unrealistically large, thus rendering the provisions unsafe. On the other hand, the alternative notional member removal provisions are more performance based, but these are applied with conventional design checks, and hence they ignore the beneficial effects of such nonlinear phenomena as catenary and arching actions.

A further significant shortcoming of the notional member removal provisions ${ }^{3}$ is the assumption of a static structural response, when the failure of vertical members under extreme events, such as blast and impact, is a highly dynamic phenomenon. In this respect, sudden column loss represents a more appropriate design scenario, which includes the dynamic influences yet is event-independent. While such a scenario is not identical in dynamic effect to column damage resulting from impact or blast, it captures the influence of column failure occurring over a relatively short duration, and it can also be considered as a standard dynamic test of structural robustness.

In this paper, a simplified approach is proposed for progressive collapse assessment of multistorey building structures subject to sudden column loss, which offers a quantitative framework for the consideration of such important issues as ductility, redundancy and energy absorption. The proposed approach can be directly applied in design practice, and importantly 
it enables the quantification of structural robustness for sudden column loss scenarios. Following presentation of the essential components of the new approach, its application is demonstrated for a typical multi-storey steel-framed composite building. In the process, some important conclusions are reached on the inherent robustness of such structures, the factors influencing their robustness, and the general adequacy of current regulations.

\section{MULTI-LEVEL ASSESSMENT APPROACH}

When a multi-storey building is subjected to sudden column loss (Fig. 1), the ensuing structural response is dynamic, leading for real steel-framed buildings to a considerable concentration of deformations in the connections within the floors above, provided the remaining columns can take the redistributed gravity load. The failure of these floors on the lower parts of the structure is largely determined by the maximum deformation demands on the connections in relation to their ductility supply. This mode of failure defines a limit state which forms the basis for quantifying the robustness of multi-storey buildings under sudden column loss scenarios.

The proposed approach utilises three main stages for evaluating the above limit state:

i) nonlinear static response, which considers the damaged structure under gravity loading;

ii) simplified dynamic assessment, which uses energy conservation to estimate the maximum dynamic response; and,

iii) ductility assessment, which establishes the ductility demand in connections at the maximum dynamic response and compares it to the ductility supply.

The proposed assessment framework may be applied at the overall structural level (Fig. 1) or at various sub-structural levels (Fig. 2), according to the required modelling detail and the feasibility of model reduction. At the first level, consideration may be given to the affected bay of the multi-storey building only (Fig. 2a), with appropriate boundary conditions to represent the interaction with the surrounding structure. Provided the surrounding columns can resist the redistributed load, further model reduction may consider only the floors above 
the lost column where deformation is concentrated (Fig. 2b). If additionally the affected floors are identical in terms of structure and loading, the axial force in the columns immediately above the lost column becomes negligible, and a reduced model consisting of a single floor system may be considered (Fig. 2c). Finally, ignoring planar effects within the floor slab, individual steel/composite beams may be considered at the lowest level of model reduction (Fig. 2d), subject to appropriate proportions of the gravity load. It is worth noting that only the first stage of assessment, namely the nonlinear static response, is influenced by the level of structural idealisation. Furthermore, significant benefits can still arise from considering the nonlinear static response at the lower levels of structural idealisation, even if the relevant conditions of model reduction do not apply, since this may be used directly to obtain the response at higher levels, as discussed in the following section.

\section{NONLINEAR STATIC RESPONSE}

Considering the simplified structural system depicted in Fig. 3, the sudden removal of the bottom column (Fig. 3a) is similar in effect to sudden application of the gravity load $\left(\mathrm{P}_{\mathrm{O}}\right)$ on the same structure, particularly when the structure sustains significant deformations as a result. This sudden application of gravity loading is associated with dynamic effects, where the deformation state corresponding to the maximum dynamic response (Fig. 3b) establishes the ductility demands that must be met to avoid failure. The proposed approach is based on the simplifying assumption that the maximum dynamic response can be estimated with reasonable accuracy from the nonlinear static response under amplified gravity loading $\left(\lambda_{d} \mathrm{P}_{\mathrm{o}}\right.$ ) (Fig. 3c), thus removing the need for detailed nonlinear dynamic analysis. Accordingly, the nonlinear static response of the structure, excluding the lost column, is required under gravity loading that is varied according to a scaling factor $\left(\mathrm{P}=\lambda \mathrm{P}_{\mathrm{O}}\right)$, where a typical response is shown in Fig. 4. This nonlinear static response forms the basis for establishing the maximum dynamic response $\left(\mathrm{u}_{\mathrm{d}}\right)$, according to the simplified dynamic assessment method proposed in Section 4. 


\subsection{Detailed Models}

Detailed modelling of the nonlinear static response can be considered at the various levels of structural idealisation (Fig. 2), as required, and this typically involves the use of advanced nonlinear finite elements.

On the beam level (Fig. 2d), detailed modelling allows for geometric and material nonlinearity typically through the use of elasto-plastic beam-column elements ${ }^{4}$, and considers the nonlinear connection response most effectively using a component-based method similar to that introduced in $\mathrm{EC}^{5}$. As a result, the influences of such nonlinear phenomena as material plasticity, arching and catenary action are readily accounted for, leaving aside for now the issue of ductility supply and its effect on the full realisation of such phenomena. Detailed modelling on this level has the additional benefit of enabling the realistic representation of composite action between the steel beam and the floor slab, including the influence of partial / full shear connection.

Similar benefits arise with detailed modelling on higher levels of structural idealisation (Fig. 2a-c), in addition to the realistic treatment of two-dimensional membrane effects within the floor slab. This is typically achieved using advanced shell elements for the slab accounting for geometric and material nonlinearity ${ }^{6}$, which are coupled to the beam elements to represent the integrated nonlinear floor response ${ }^{7}$.

\subsection{Simplified Models}

The proposed assessment framework supports the use of simplified models for determining the nonlinear static response at various levels of structural idealisation, thus facilitating progressive collapse assessment in the design process. Simplified and detailed models may also be combined, where detailed modelling could be considered at the lower levels of structural idealisation, with simplified modelling applied to assemble the nonlinear static response at the higher levels. 


\subsubsection{Individual beams}

Simplified models can be used for representing the nonlinear static response of individual beams (Fig. 2d), provided they account for such nonlinear phenomena as material plasticity, arching and catenary action, as relevant to the beam under consideration. Simplified beam models were developed for the elasto-plastic response including catenary action ${ }^{8-10}$, mainly for application in blast and fire assessment. Nevertheless, such models still require some development, principally in relation to realistic connection modelling, before they can be applied more generally in the present context. In any case, as shown in the application study, the limited ductility supply of typical partial-strength connection details prevents the development of full catenary action, and hence the consideration of catenary effects in simplified modelling is not absolutely necessary. On the other hand, compressive arching action could play a more significant role in the presence of axial restraint, and hence is much more important to consider. This is particularly true for steel/composite beams with partial strength connections, where the double-span condition resulting from column removal is associated with offset centres of rotations at the support and internal connections, thus leading to significant compressive arching, as illustrated in Fig. 5. Although simplified modelling of compressive arching is feasible, further developments are again required principally in relation to realistic connection modelling.

In view of the current state of simplified modelling, detailed models based on nonlinear finite elements remain the most effective means for establishing the nonlinear static response of individual beams, including composite action and realistic connection modelling. However, this can still be combined with simplified modelling at the floor level for more practical application in the design process, as discussed next.

\subsubsection{Individual floors}

Simplified modelling can be used to approximate the nonlinear static response of a floor system (Fig. 2c) as a grillage assembly of individual beams. With the nonlinear static response of the individual beams determined from either detailed (Section 3.1) or simplified 
(Section 3.2.1) models, the corresponding $\left(\mathrm{P}_{\mathrm{i}}, \mathrm{u}_{\mathrm{s}, \mathrm{i}}\right)$ relationship for beam (i) provides a measure of the energy absorption characteristics of the beam:

$$
\delta U_{\mathrm{i}}=\alpha_{\mathrm{i}} \mathrm{P}_{\mathrm{i}} \delta \mathrm{u}_{\mathrm{s}, \mathrm{i}}
$$

where with reference to Fig. 5 (upper inset), $\alpha_{i}$ is a work-related weighting factor which depends on the assumed load distribution on the beam and on the incremental deformation mode. For example, for a point load at midspan and for a uniformly distributed load with the bilinear deformation mode illustrated in Fig. 5 (lower insets), the values of $\alpha_{i}$ are obtained as:

$$
\alpha_{i}= \begin{cases}1 & \text { (point load) } \\ 0.5 & \text { (uniformly distributed load) }\end{cases}
$$

The above values also apply to a cantilever beam for a point load acting at the cantilever tip and for a uniformly distributed load assuming a plastic hinge at the support.

In a grillage approximation of a floor system, the various beams share the loading in a complex manner, especially in the nonlinear range of response. However, assuming a dominant mode of deformation for the overall floor system, the detail of load sharing between the individual beams becomes relatively unimportant. In this case, it is sufficient to obtain the individual beam responses under a relatively arbitrary load distribution (e.g. uniformly distributed loading), with the primary objective of establishing their energy absorption characteristics for the assumed mode of deformation. Considering such a mode for the overall floor system (e.g. Fig. 6), the grillage response is easily assembled from the responses of individual beams by equating the incremental external work and internal absorbed energy:

$$
\left(\delta W=\alpha \mathrm{P} \delta \mathrm{u}_{\mathrm{s}}\right) \equiv\left(\sum_{\mathrm{i}} \delta U_{\mathrm{i}}=\sum_{\mathrm{i}} \alpha_{\mathrm{i}} \mathrm{P}_{\mathrm{i}} \delta \mathrm{u}_{\mathrm{s}, \mathrm{i}}\right)
$$

where $\alpha$ can be determined for the floor system in a similar manner to individual beams, as discussed before:

$$
\alpha=0.25 \text { (uniformly distributed load) }
$$


With the compatibility between the component and system deformations expressed in terms of appropriate geometric parameters $\left(\beta_{\mathrm{i}}\right)$ :

$$
\mathrm{u}_{\mathrm{s}, \mathrm{i}}=\beta_{\mathrm{i}} \mathrm{u}_{\mathrm{s}}
$$

the overall system response is assembled from individual beam responses according to:

$$
\alpha \mathrm{P}=\sum_{\mathrm{i}} \alpha_{\mathrm{i}} \beta_{\mathrm{i}} \mathrm{P}_{\mathrm{i}} \Rightarrow \mathrm{P}=\frac{1}{\alpha} \sum_{\mathrm{i}} \alpha_{\mathrm{i}} \beta_{\mathrm{i}} \mathrm{P}_{\mathrm{i}}
$$

This provides a direct relationship between $\mathrm{P}$ and $\mathrm{u}_{\mathrm{s}}$ for the floor system, since $\mathrm{P}_{\mathrm{i}}$ for each beam is a function of the corresponding $\mathrm{u}_{\mathrm{s}, \mathrm{i}}$ that is in turn related to $\mathrm{u}_{\mathrm{s}}$ according to (5). Note that the $\alpha$ and $\alpha_{\mathrm{i}}$ factors in the illustration of Fig. 6 correspond to the assumption of uniformly distributed loading on the floor and individual beams, though alternative load distributions may also be used for the beams subject to appropriate modification of $\alpha_{i}$, as discussed above.

\subsubsection{Multiple floors}

In a similar way, simplified modelling can be used to obtain the nonlinear static response of the system of multiple floors above the failed column (Fig. 2b) by assembling the responses of individual floors, each of which may be determined from either detailed (Section 3.1) or simplified (Section 3.2.2) models:

$$
\alpha P=\sum_{j} \alpha_{j} P_{j} \Rightarrow P=\frac{1}{\alpha} \sum_{j} \alpha_{j} P_{j}
$$

With reference to Fig. $7, \alpha_{j}$ and $P_{j}$ represent the work-related weighting factor and total load for floor (j), respectively, assuming a dominant deformation mode in which the floor displacement $\left(\mathrm{u}_{\mathrm{s}, \mathrm{j}}\right)$, measured along the failed column line, is constant for all floors. Conveniently, when using simplified modelling at the floor level, as discussed in the previous section, the tem $\left(\alpha_{j} P_{j}\right)$ for a specific floor can be directly obtained as the assembly of beam contributions ( $\sum_{i} \alpha_{i} \beta_{i} P_{i}$ ) according to (6). On the other hand, $\alpha$ and $P$ in (7) represent now the work-related weighting factor and total load for the overall multiple floor system, respectively, where for uniformly distributed loading on all floors: 
$\alpha=0.25$ (uniformly distributed loads)

Again, the above establishes a direct relationship between $\mathrm{P}$ and $\mathrm{u}_{\mathrm{s}}$ for the multiple floor system, since $P_{j}$ for each floor is a function of the corresponding $u_{s, j}$ that is identical to $u_{s}$.

\section{SIMPLIFIED DYNAMIC ASSESSMENT}

Existing design codes ${ }^{12,13}$ which consider sudden column loss scenarios as a standard test of structural robustness, suggest a static assessment based on a constant dynamic amplification factor $\left(\lambda_{d}=2\right)$ for gravity loading, which is correct only for a linear elastic response. For a nonlinear elasto-plastic response, this amplification factor hugely over-estimates the strength/ deformation demands, and therefore it does not offer a realistic assessment.

A simplified approach, proposed by $\operatorname{Izzuddin}^{11}$, is instead employed to determine the maximum dynamic deformation demands considering the influence of nonlinearity in the structural response, where sudden column loss is considered similar in effect to sudden application of the gravity load on the damaged sub-structure. In the initial stages of the dynamic response, the gravity load exceeds the static structural resistance, and the differential work done over the incremental deformations is transformed into additional kinetic energy, thus leading to increasing velocities. As the deformations increase, the static resistance exceeds the gravity loading, and the differential energy absorbed accounts for a reduction in the kinetic energy, thus leading to decreasing velocities. Assuming a response dominated by a single deformation mode, the maximum dynamic response is achieved when the kinetic energy is reduced back to zero, and hence when the work done by the gravity loads becomes identical to the energy absorbed by the structure. It is noted that the static resistance at the maximum dynamic response exceeds the applied loading, and hence dynamic rather than static equilibrium is achieved.

This principle is illustrated in Figs. 8a-b for two levels of suddenly applied gravity loading ( $\mathrm{P}=\lambda_{1} \mathrm{P}_{\mathrm{o}}, \mathrm{P}=\lambda_{2} \mathrm{P}_{\mathrm{o}}$ ), where the nonlinear static load-deflection response is employed to determine the corresponding maximum dynamic displacements $\left(\mathrm{u}_{\mathrm{d}, 1}, \mathrm{u}_{\mathrm{d}, 2}\right)$. Assuming $\mathrm{a}$ dominant deformation mode, the equivalence between external work and internal energy is obtained in each case when the two depicted hatched areas become identical. Therefore, the 
level of suddenly applied gravity loading $\left(\mathrm{P}_{n}=\lambda_{n} \mathrm{P}_{\mathrm{o}}\right)$ that leads to a specific maximum dynamic displacement $\left(\mathrm{u}_{\mathrm{d}, \mathrm{n}}\right)$ is easily obtained from the nonlinear static response as:

$$
\mathrm{P}_{\mathrm{n}}=\lambda_{\mathrm{n}} \mathrm{P}_{\mathrm{o}}=\frac{1}{\mathrm{u}_{\mathrm{d}, \mathrm{n}}} \int_{0}^{\mathrm{u}_{\mathrm{d}, \mathrm{n}}} \mathrm{Pdu} \mathrm{d}_{\mathrm{s}}
$$

where the integral represents the area under the nonlinear static $\left(\mathrm{P}, \mathrm{u}_{\mathrm{s}}\right)$ curve for displacements up to $\mathrm{u}_{\mathrm{d}, \mathrm{n}}$.

The application of the proposed approach is considerably simplified if the suddenly applied gravity loading $\left(\mathrm{P}_{\mathrm{n}}\right)$ is plotted against the maximum dynamic displacement $\left(\mathrm{u}_{\mathrm{d}, \mathrm{n}}\right)$, leading to $\mathrm{a}\left(\mathrm{P}, \mathrm{u}_{\mathrm{d}}\right)$ curve expressing the maximum nonlinear dynamic response, as depicted in Fig. 8c. This is referred to as the pseudo-static response, since it can be assembled similar to the nonlinear static response at different levels of structural idealisation, while expressing the maximum dynamic response due to suddenly applied loading. With $\mathrm{P}_{\mathrm{o}}$ representing the actual gravity load, the maximum dynamic displacement can be readily obtained from the pseudo-static response at $\left(\mathrm{P}=\mathrm{P}_{\mathrm{o}}\right)$, as illustrated in Fig. 8c, and this can then be used to establish the ductility demands in the various connections, as discussed next.

\section{DUCTILITY ASSESSMENT}

In this final stage of assessment, the maximum dynamic displacement $\left(\mathrm{u}_{\mathrm{d}}\right)$, obtained from the pseudo-static response, is employed to establish the ductility demands in the various connections, which are then compared to the respective ductility supplies to evaluate the limit state associated with floor system failure. Regardless of the adopted level of structural idealisation, the connection deformation demands are directly related to $\mathrm{u}_{\mathrm{d}}$, typically as the outcome of detailed modelling at lower levels, combined with the compatibility condition of the assembled system at a higher level, as given for example by (5) for the assembled floor grillage system.

The connection deformations at $\mathrm{u}_{\mathrm{d}}$ can be transformed into ductility demands in various components of the connection, which are then compared to ductility supply to establish the limit state, as discussed briefly in the subsequent application study. It is noted that, while 
there is a need for more experimental work to establish the ductility supply of various connection types under general deformation conditions, the proposed assessment framework could readily employ such data as and when it becomes available.

\section{MEASURES OF ROBUSTNESS}

Several factors have long been associated with structural robustness, including i) energy absorption capacity, ii) ductility supply, and iii) redundancy. In the context of buildings subject to sudden column removal, it can be shown that each of these factors can have positive as well as negative influences on the limit state, and hence these are not individually suitable as measures of structural robustness.

Considering first the energy absorption capacity, it is evident with reference to Fig. 8 that the energy demand on the system can be expressed as:

Energy demand $\propto$ Gravity load $\times$ Ductility demand

The ductility demand and thus the energy demand on the system level, depends on the stiffness of the pseudo-static response, with a larger stiffness typically leading to a smaller energy demand. Therefore, it is quite possible for a structure with a relatively large energy absorption capacity to be inadequate due to an even larger energy demand, while another structure with a smaller energy absorption capacity, but with a stiffer pseudo-static response, may be adequate due to a much smaller energy demand.

On the other hand, redundancy offers a guaranteed benefit in conventional strength-based plastic design, where the plastic strength of the contributing components is typically achieved at relatively small displacements well before ductility limits are reached. In the proposed progressive collapse assessment, reliance is placed on the ultimate strength, which is difficult to achieve for all contributing components before a ductility limit is reached. In this context, increased redundancy cannot be guaranteed to be beneficial, and may to the contrary be detrimental, especially if its effect is to redistribute loads towards components which are already close to the ductility limit. 
Finally, increased ductility supply on a system level is beneficial only if it is associated with a corresponding increase in pseudo-static capacity. On an individual component level, increased ductility supply may even be undesirable, particularly if this leads to load redistribution towards other critical components within the system. In this case, reduced component ductility could be more beneficial, in which case the corresponding component would be designed as a fuse.

It is evident from the above discussion that the three commonly advocated indicators are inadequate as single measures of structural robustness for sudden column loss scenarios. In this context, it is proposed that the single measure of structural robustness is the system pseudo-static capacity, which readily accounts for the combined influence of energy absorption capacity, redundancy and ductility at various levels of structural idealisation.

\section{APPLICATION STUDY}

The robustness of a multi-storey steel-composite framed building is evaluated here using the proposed approach, where consideration is given to sudden column removal at the periphery of the structure. It is assumed that the floors above the removed column are identical in terms of structure and loading, and thus the assessment approach can be applied at the floor level of structural idealisation (Fig. 2c). A schematic diagram of the affected floor plate is shown in Fig. 9, where full details of the beams, partial strength connections, composite slab and gravity loading can be found elsewhere ${ }^{14}$.

Although assessment is undertaken at the level of the floor plate, it is still useful to establish the individual pseudo-static response characteristics of individual beams. Firstly, this enables the relative resistance of beams under apportioned gravity loading to be assessed, leading to the identification of 'weak links'. Secondly, the individual beam responses can be directly assembled to obtain the floor plate response according to a grillage approximation, as discussed in Section 3.2.2.

Detailed finite element modelling is employed to establish the nonlinear static response of individual beams ${ }^{14}$, accounting for geometric and material nonlinearity, composite action, 
and the nonlinear connection response using a component-based approach. The pseudo-static response of individual beams, reflecting the influence of dynamic amplification under sudden column removal, is obtained from the nonlinear static response according to Section 4, and is used for the grillage approximation of the floor plate pseudo-static capacity. In determining the pseudo-static capacity of individual beams, and hence the assembled floor plate, the limiting displacement is that which corresponds to a ductility demand in one of the connection components, as obtained from detailed beam modelling, exceeding the ductility supply. In the present study, the ductility supply of steel connection components is based on some limited experimental data ${ }^{15,16}$ coupled with practical considerations ${ }^{14}$, while failure of the steel reinforcement in composite joints is also accounted for ${ }^{14,17}$.

Considering first the double-span edge beam (Fig. 9), which utilises partial-depth flexible end-plate connections, the response is obtained for the bare steel and composite design alternatives, where the influence of axial restraint at the remote ends of the adjacent bays is also investigated. Typically for the composite beam subject to axial restraint, the nonlinear static response is dominated by compressive arching action ${ }^{14}$, which improves the beam resistance considerably. With an apportioned gravity service load of $177 \mathrm{kN}$, the obtained pseudo-static responses corresponding to the various assumptions of axial restraint and reinforcement ratios in the composite beams are shown in Fig. 10, where several significant conclusions can be made. Firstly, the bare steel beam is clearly incapable of withstanding the suddenly applied apportioned gravity load, regardless of axial restraint, despite fulfilling the prescriptive tying force requirements. Secondly, the composite beam is much more robust, potentially capable of fully resisting the apportioned load with the provision of axial restraint and/or additional reinforcement in the composite joints. Finally, the ductility supply of the composite beams is limited to a midspan displacement of around $400 \mathrm{~mm}$, corresponding to a rotational ductility supply in the connections of around $4^{\circ}(70 \mathrm{mrad})$, which is insufficient for the development of tensile catenary action. Even for the bare steel beams, the increased rotational ductility supply in the connections of around $6^{\circ}(100 \mathrm{mrad})$ is still insufficient for the development of full tensile catenary action. 
A similar assessment is also undertaken for a typical internal double-span secondary beam (Fig. 9), in which fin-plate connections are utilised, where the corresponding results are shown in Fig. 11. The levels of ductility supply, whether for the midspan displacement or the connection rotations, are similar to those observed for the edge beam. While significant tensile catenary action is observed for the axially restrained bare steel beam, this effect is much reduced for the composite beams, mainly due to the reduced ductility supply that is also accompanied with an increased effective cross-section depth. Nevertheless, it is clear that the internal secondary beam offers a grossly inadequate dynamic resistance to the apportioned gravity load of $195 \mathrm{kN}$, regardless of axial restraint, composite action and the associated reinforcement ratio.

With the internal secondary beams largely inadequate to resist normally apportioned loads, it is yet possible for the overall plate grillage, assembled according to Section 3.2.2, to be sufficiently robust. In this respect, the transverse primary beam (Fig. 9) provides some cantilever resistance, but importantly it offers the necessary redundancy to transfer excess loads from the internal beams to the edge beam. With the ductility of the transverse beam being generally non-critical, the pseudo-static resistance of the assembled floor grillage is obtained for various cases ${ }^{14}$ as in Table 1 . Given a total service gravity load on the floor plate of $742 \mathrm{kN}$, the importance of composite action, the associated reinforcement ratio and axial restraint is evident from the tabulated results, where it can be seen that the composite floor with the largest reinforcement ratio $(2 \%)$ and subject to axial restraint provides an adequate level of robustness. Importantly, the bare steel design is clearly deficient despite satisfying the prescriptive tying force requirements ${ }^{1,2}$, which confirms the inadequacy of the current Building Regulations towards ensuring structural robustness with the neglect of ductility issues.

\section{CONCLUSION}

A multi-level framework is proposed for simplified progressive collapse assessment of building structures subject to sudden column loss, which provides a realistic means of quantifying structural robustness. Three stages are employed within this framework: i) 
determination of the nonlinear static response, ii) simplified dynamic assessment, and iii) ductility assessment.

Following a presentation of the main components of the proposed framework, it is shown that the proposed pseudo-static capacity can be used for a single measure of robustness, which accounts for the combined influence of energy absorption capacity, redundancy and ductility on the overall system level. It is believed that the proposed approach offers an appropriate framework for moving the debate surrounding structural robustness forward from the general to the quantifiable.

Finally, the application of the proposed approach is demonstrated on a typical multi-storey steel-composite building subject to sudden column removal at the periphery. A main outcome from this study is that such structures can be made sufficiently robust with the addition of reinforcement in the composite joint regions, provided due allowance is taken of compressive arching action that develops under axial restraint. Importantly, the rotational ductility supply offered by typical steel and composite connections of between $4^{\circ}$ to $6^{\circ}(70 \mathrm{mrad}$ to $100 \mathrm{mrad})$ is inadequate for the development of full tensile catenary action, and therefore reliance should be placed mainly on bending and compressive arching resistance for the provision of robustness under column removal scenarios.

\section{ACKNOWLEDGMENT}

The authors would like to acknowledge the financial support provided for this work by ARUP and EPSRC under a Case award scheme. The significant input into this project of several ARUP staff, especially Faith Wainwright, Mike Banfi and Michael Willford, is also gratefully acknowledged. 


\section{REFERENCES}

1. OfFice of the Deputy Prime Minister. The Building Regulations 2000, Part A, Schedule 1: A3, Disproportionate Collapse, 2004, London, UK.

2. British Standards InStitution. BS 5950: Structural Use of Steelwork in Buildings, Part 1: Code of Practice for Design - Rolled and Welded Sections, 2001, London, UK.

3. Ove Arup \& Partners LtD. A Scoping Study - The Building Regulations: Post September 11, 2003, Office of the Deputy Prime Minister, London, U.K.

4. IZZUDDin B.A. and ElnASHAi A.S. Adaptive Space Frame Analysis - Part II: Distributed Plasticity Approach. Proceedings of the Institution of Civil Engineers - Structures and Buildings, 1993, 99, pp. 317-326.

5. European COMMITTEE FOR STANDARDIZATION. EN 1993-1-8:2003, Eurocode 3: Design of Steel Structures - Part 1-8: Design of Joints, 2005, Brussels.

6. IZZUdDin B.A., TAO X.Y. and Elghazouli A.Y. Realistic Modelling of Composite and Reinforced Concrete Floor Slabs under Extreme Loading - Part I: Analytical Method. Journal of Structural Engineering, ASCE, 2004, 130, No. 12, pp. 1972-1984.

7. IZZUDDIN B.A. Integration of Beam-Column and Shell Elements in Large Displacement Structural Analysis. Proceedings of the International Symposium on New Perspectives for Shell and Spatial Structures, 2003, IASS-APCS 2003, Taipei, Taiwan.

8. IZZUDDIN B.A. An Improved SDOF Model for Steel Members Subject to Explosion Loading - Generalised Supports and Catenary Action, 2001, Report Prepared for FABIG Technical Note 7, The Steel Construction Institute.

9. IZZUDDIN B.A. An Advanced SDOF Model for Steel Members Subject to Explosion Loading - Material Rate Sensitivity, 2004, Report Prepared for FABIG Technical Note 10, The Steel Construction Institute.

10. YIN Y.Z. and WANG Y.C. Analysis of Catenary Action in Steel Beams Using a Simplified Hand Calculation Method - Part 1: Theory and Validation for Uniform 
Temperature Distribution. Journal of Constructional Steel Research, 2005, 61, pp. 183211.

11. IZZUDDIn B.A. Ductility Assessment for an Idealized Elasto-Plastic Structural System Subject to an Instantaneous Applied Load, 2004, Internal discussion document, Imperial College London, U.K.

12. General SERvices Administration. Progressive Collapse Analysis and Design Guidelines for New Federal Office Buildings and Major Modernization Projects, 2003, USA.

13. Department of Defense. Unified Facilities Criteria, Design of Buildings to Resist Progressive Collapse, 2005, USA.

14. Vlassis A.G. Progressive Collapse Assessment of Tall Buildings. PhD thesis, Imperial College London, 2007, University of London, UK.

15. Jarrett N.D. Axial Tests on Beam/Column Connections. BRE Client Report CR 55/90, 1990, Building Research Establishment, Garston, Watford, UK.

16. Owens G.W. and Moore, D.B. The Robustness of Simple Connections. The Structural Engineer, 1992, 70, No. 3, pp. 37-46.

17. Anderson D., Aribert J.M., Bode H. and Kronenburger, H. J. Design Rotation Capacity of Composite Joints. The Structural Engineer, 2000, 78, No. 6, pp. 25-29. 
Figure 1. Multi-storey building subject to sudden column loss

Figure 2. Sub-structural levels for progressive collapse assessment

Figure 3. Sudden column removal modelled using amplified static loading

Figure 4. Characteristic nonlinear static response under proportional load $\left(P=\lambda P_{o}\right)$

Figure 5. Compressive arching and tensile catenary actions in double-span steel beam

Figure 6. Grillage approximation of a floor system with three beams

Figure 7. Simplified model for multiple floor system consisting of three floors

Figure 8. Simplified dynamic assessment and definition of pseudo-static response

Figure 9. Floor system affected by column removal

Figure 10. Pseudo-static response of edge beam

Figure 11. Pseudo-static response of typical internal beam 
Table 1. Overall pseudo-static capacity of floor plate grillage

\begin{tabular}{cccc}
\hline $\begin{array}{c}\text { Reinforcement } \\
\text { ratio }\end{array}$ & Axial restraint & $\begin{array}{c}\text { Pseudo-static capacity } \\
(\mathrm{kN})\end{array}$ & Unity factor \\
\hline $0.87 \%$ & Yes & 599 & 0.81 \\
$2 \%$ & Yes & 774 & 1.04 \\
$2 \%$ & No & 710 & 0.96 \\
Bare steel beams & Yes & 149 & 0.20 \\
\hline
\end{tabular}




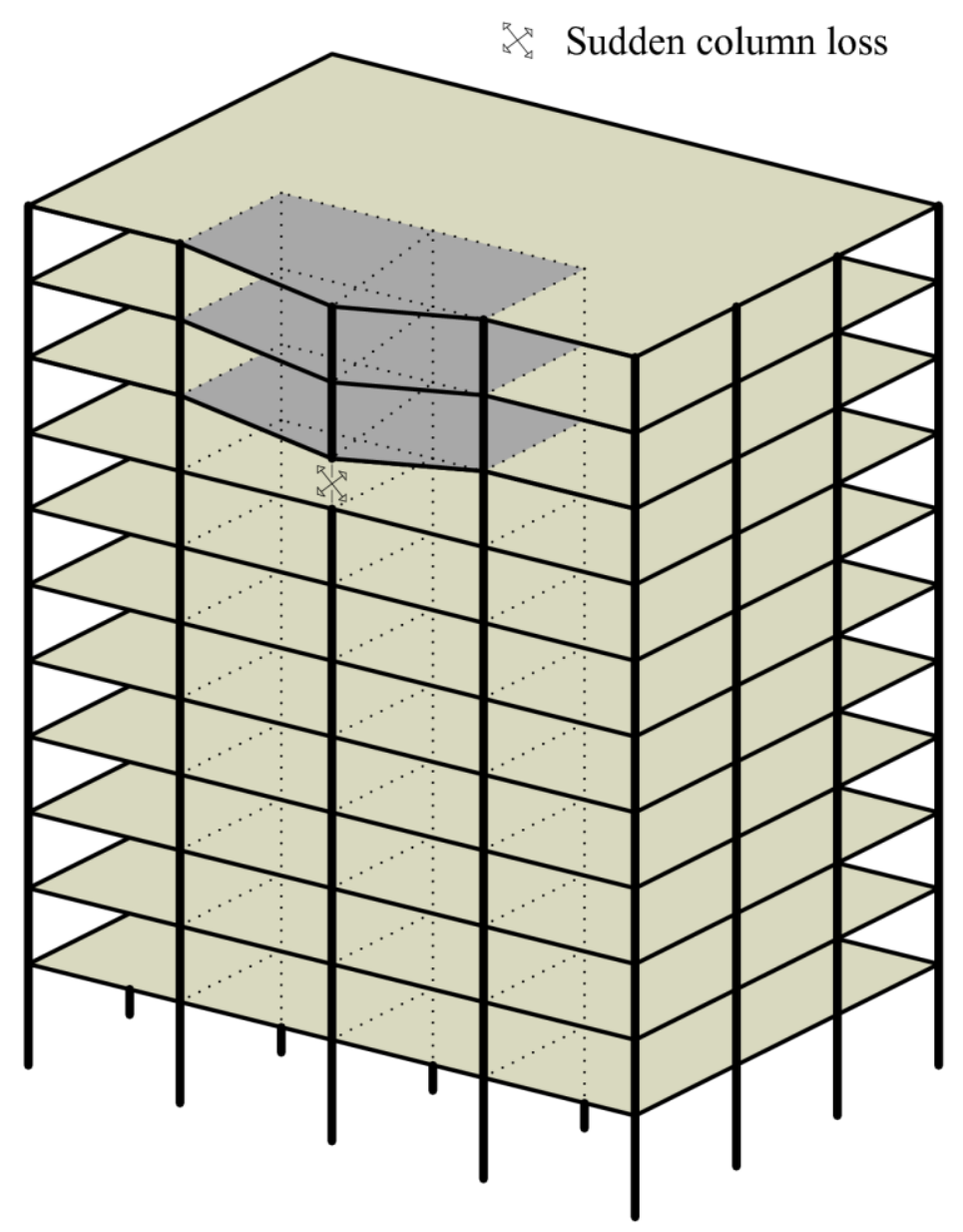

Figure 1. Multi-storey building subject to sudden column loss 
Sudden column loss

Wh Translational/rotational springs
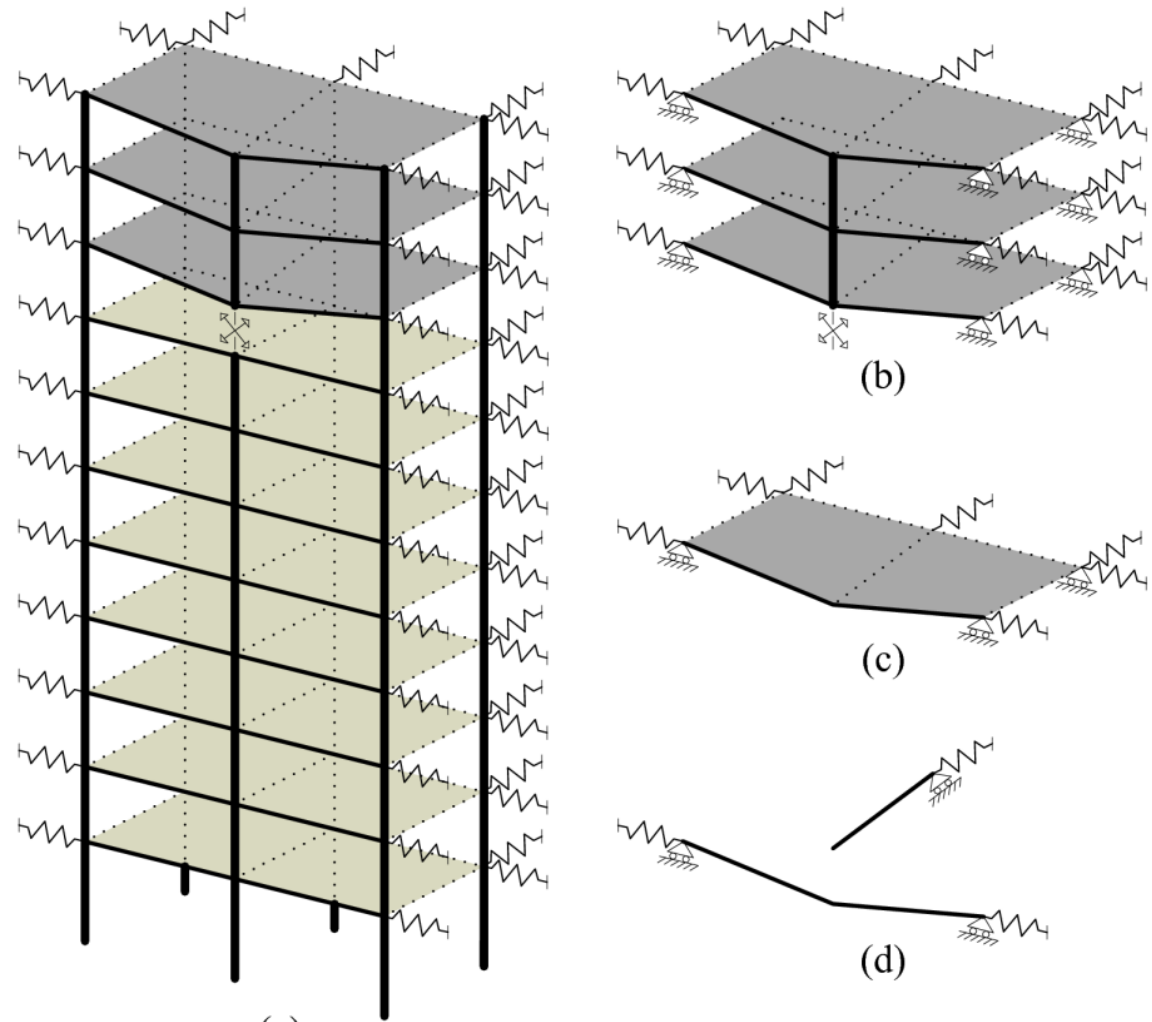

(b)

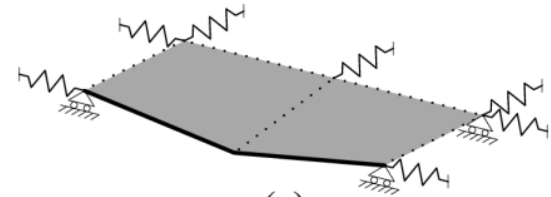

(c)

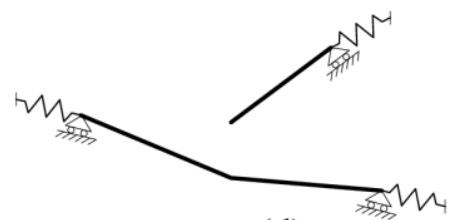

(d)

(a)

Figure 2. Sub-structural levels for progressive collapse assessment 


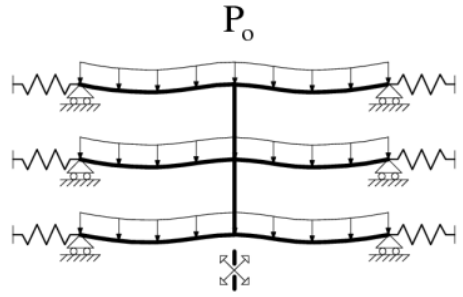

(a) Sudden column loss

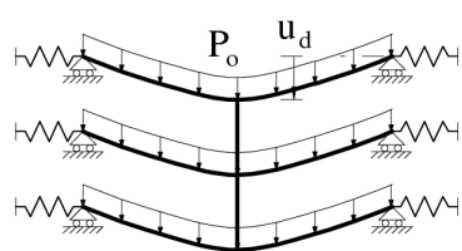

(b) Maximum dynamic response

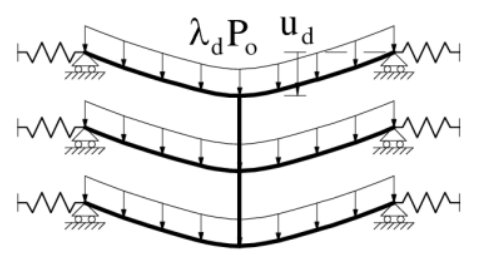

(c) Amplified static loading

Figure 3. Sudden column removal modelled using amplified static loading 


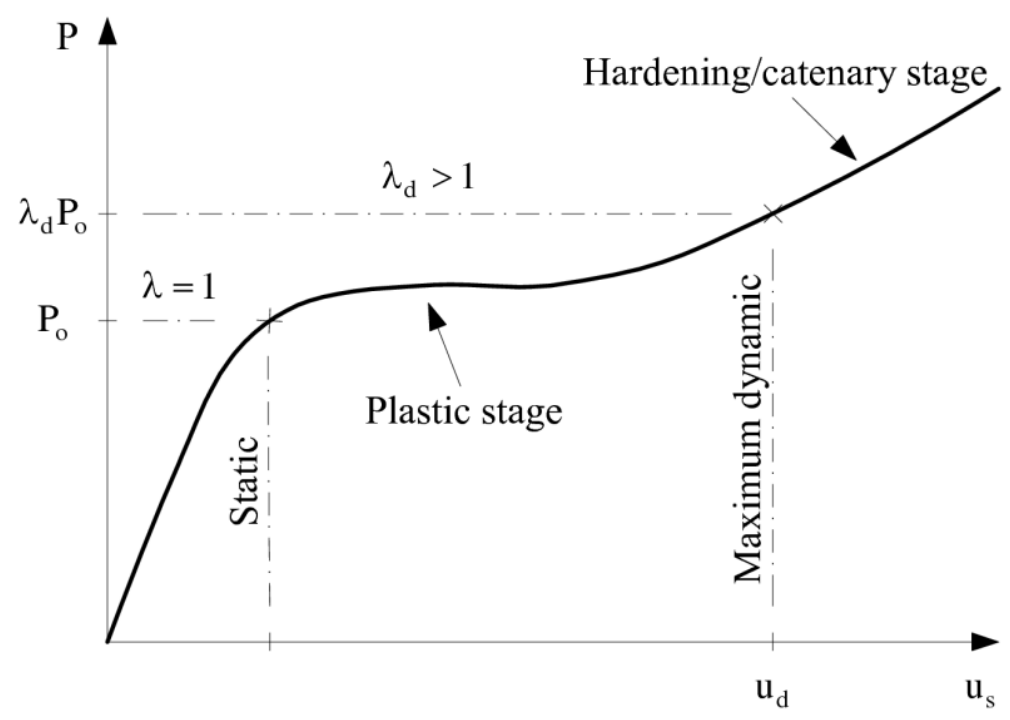

Figure 4. Characteristic nonlinear static response under proportional load $\left(\mathrm{P}=\lambda \mathrm{P}_{\mathrm{o}}\right)$ 


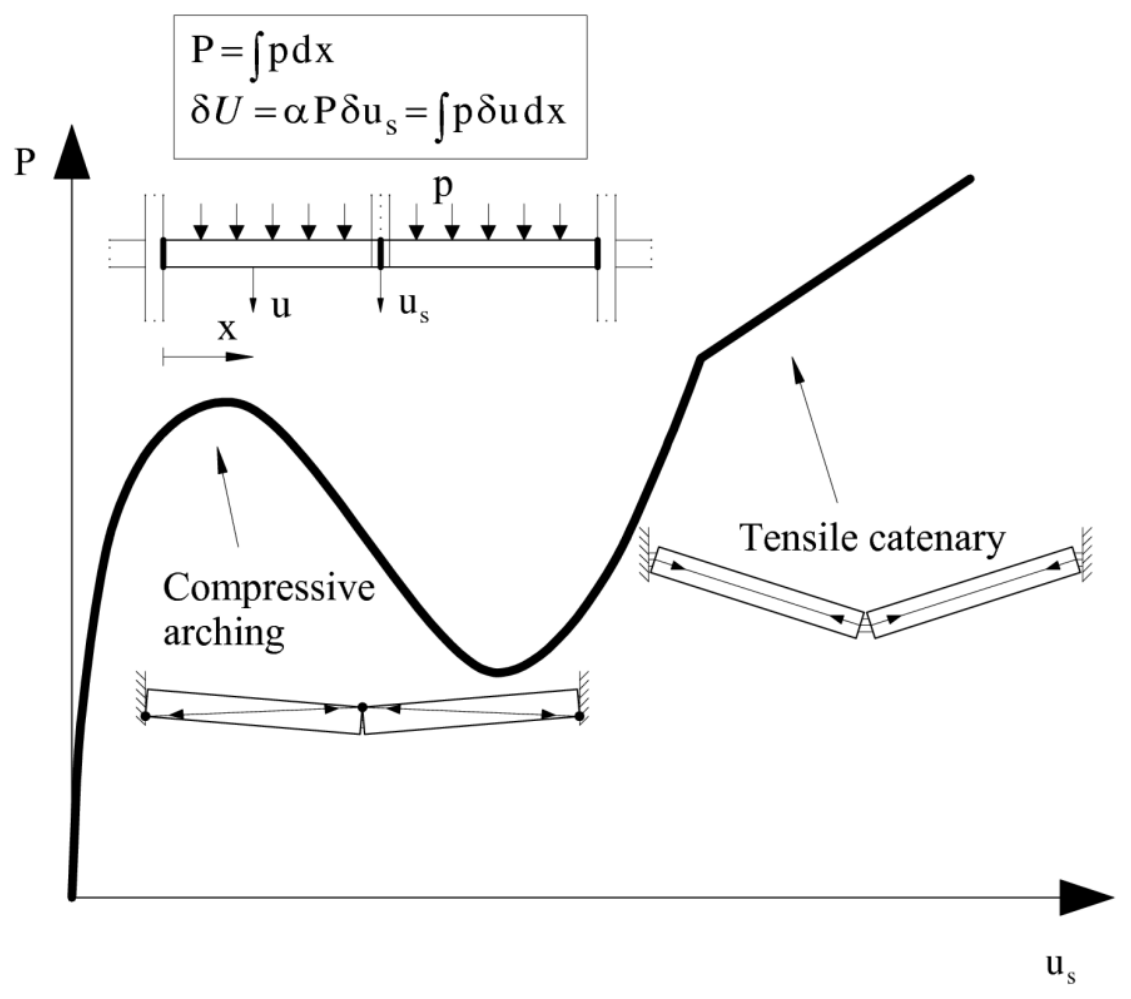

Figure 5. Compressive arching and tensile catenary actions in double-span steel beam 


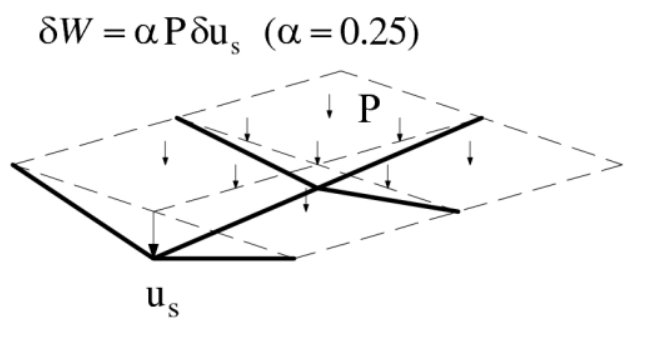

Dominant mode for floor system

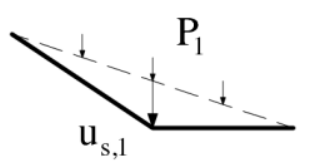

$$
\mathrm{u}_{\mathrm{s}, 1}=\beta_{1} \mathrm{u}_{\mathrm{s}} \quad\left(\beta_{1}=1\right)
$$$$
\delta U_{1}=\alpha_{1} \mathrm{P}_{1} \delta \mathrm{u}_{\mathrm{s}, 1} \quad\left(\alpha_{1}=0.5\right)
$$

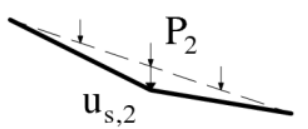

$\mathrm{u}_{\mathrm{s}, 2}=\beta_{2} \mathrm{u}_{\mathrm{s}}\left(\beta_{2}=0.5\right)$

$\delta U_{2}=\alpha_{2} \mathrm{P}_{2} \delta \mathrm{u}_{\mathrm{s}, 2}\left(\alpha_{2}=0.5\right)$

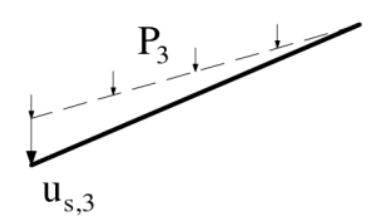

$\mathrm{u}_{\mathrm{s}, 3}=\beta_{3} \mathrm{u}_{\mathrm{s}} \quad\left(\beta_{3}=1\right)$

$\delta U_{3}=\alpha_{3} \mathrm{P}_{3} \delta \mathrm{u}_{\mathrm{s}, 3}\left(\alpha_{3}=0.5\right)$

Individual beam modes

Figure 6. Grillage approximation of a floor system with three beams 


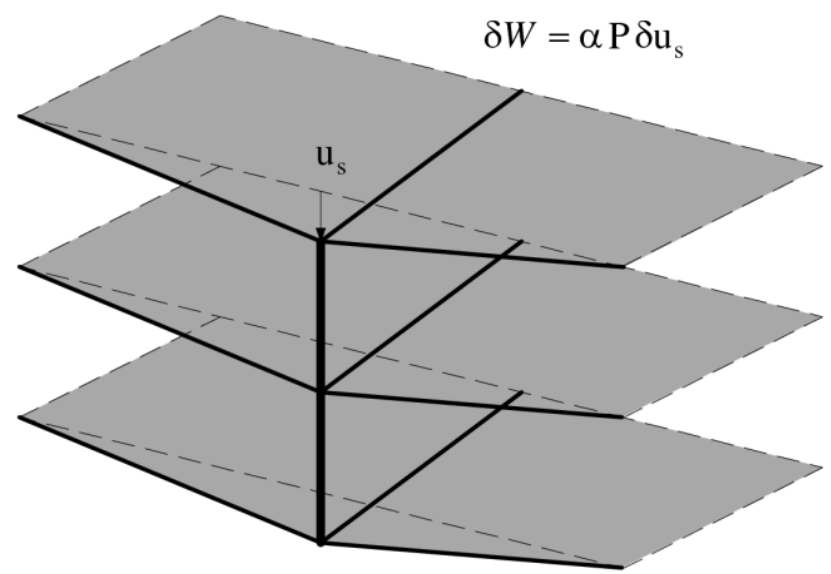

$$
\mathrm{u}_{\mathrm{s}, \mathrm{j}}=\mathrm{u}_{\mathrm{s}}, \quad \delta U_{\mathrm{j}}=\alpha_{\mathrm{j}} \mathrm{P}_{\mathrm{j}} \delta \mathrm{u}_{\mathrm{s}} \quad(\mathrm{j}=1,3)
$$

Figure 7. Simplified model for multiple floor system consisting of three floors 


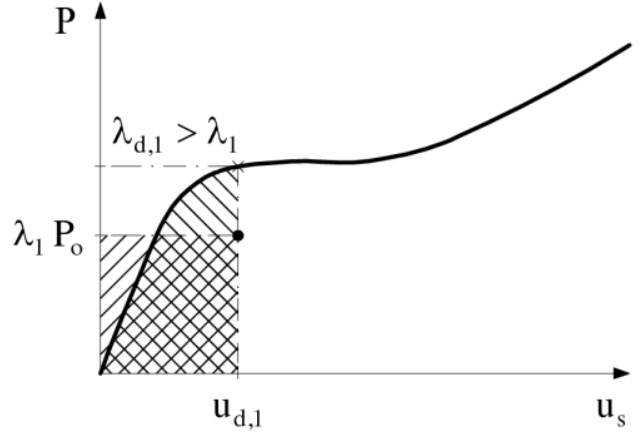

(a) Dynamic response $\left(\mathrm{P}=\lambda_{1} \mathrm{P}_{\mathrm{o}}\right)$

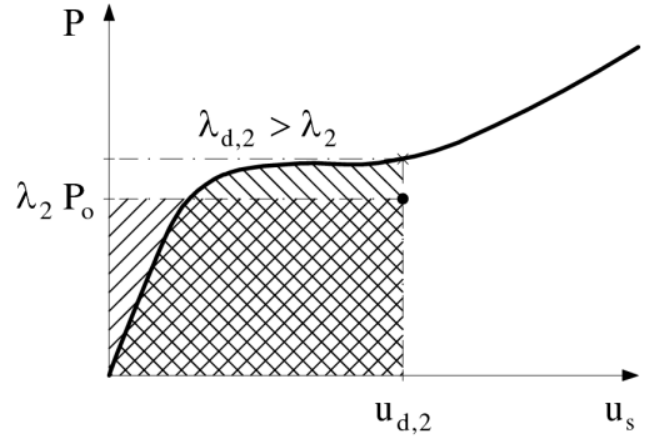

(b) Dynamic response $\left(\mathrm{P}=\lambda_{2} \mathrm{P}_{\mathrm{o}}\right)$

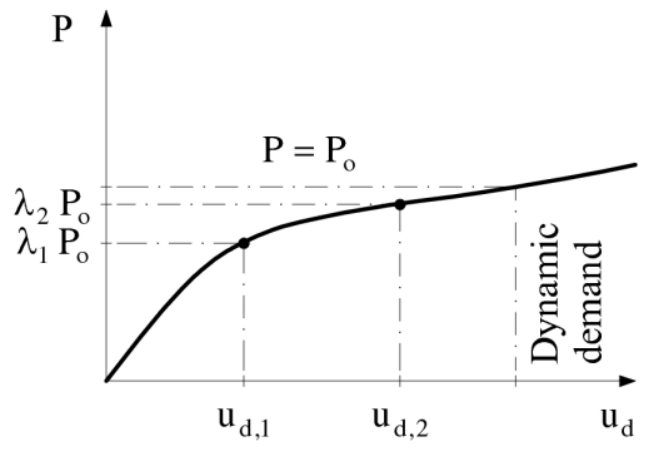

(c) Pseudo-static response

Figure 8. Simplified dynamic assessment and definition of pseudo-static response 


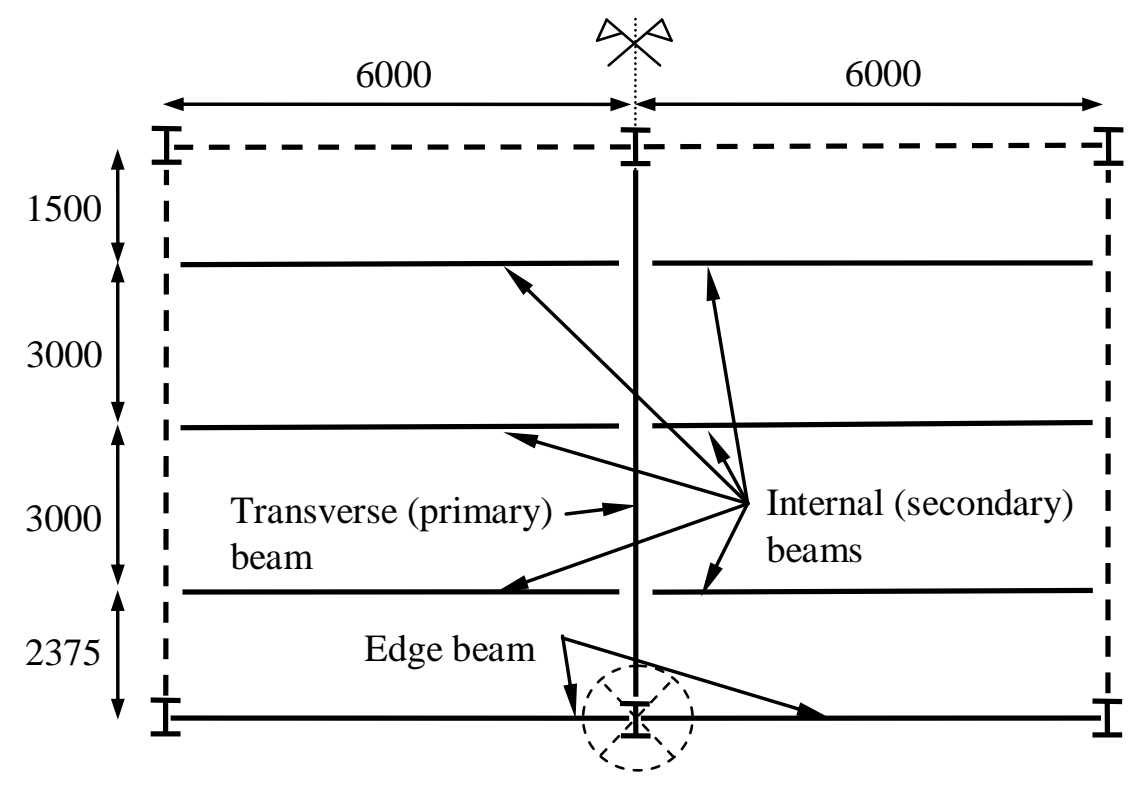

Removed column

Figure 9. Floor system affected by column removal 


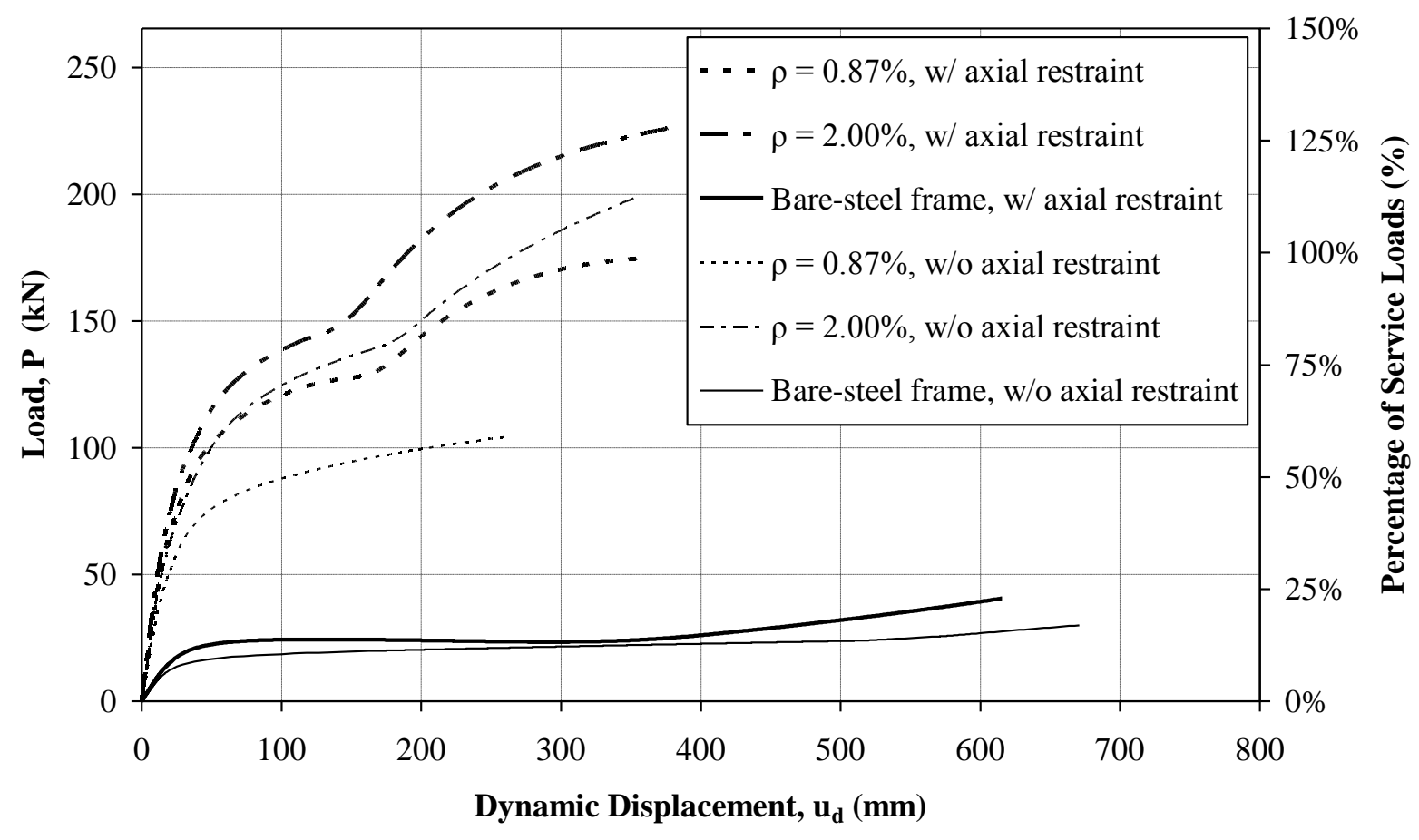

Figure 10. Pseudo-static response of edge beam 


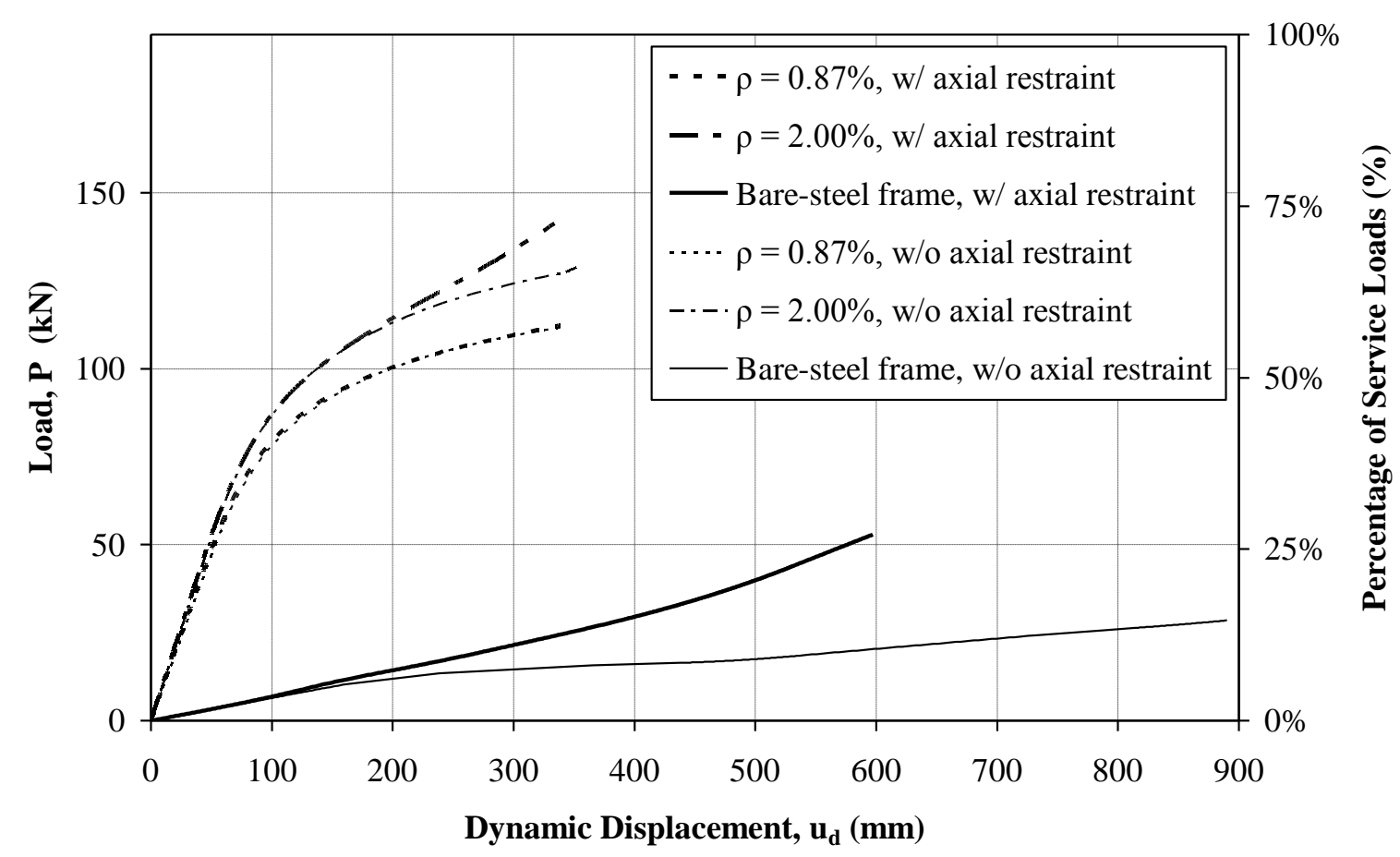

Figure 11. Pseudo-static response of typical internal beam 